\title{
The effect of neuroleptic drug treatment on plasma fibrinogen concentrations in schizophrenic
} states

\author{
C. J. BRACKENRIDGE AND I. H. JONES \\ From the Department of Psychiatry, University of Melbourne, \\ Victoria, Australia
}

Reports of a protein anomaly in functional psychoses have been steadily accumulating since the subject was reviewed by Fessel (1962a). As a result, concepts of schizophrenia as a metabolic and autoimmune disorder (Fessel, 1962b; Heath and Krupp, 1967; Heath, Krupp, Byers, and Liljekvist, 1967a, b) associated with a blood factor have been developed. Following the report by Bergen, Koella, Freeman, and Hoagland (1962) that the replacement of the plasma of psychotic patients by serum led to loss of physiological activity after injection into rats, Seal, Swaim, and Eist (1967) examined the plasma fibrinogen content of 13 newly admitted, and 80 institutionalized schizophrenic subjects. The observed increase in both cases was highly significant $(P<0.001)$ when compared with values derived from 20 normal persons. Their results appeared to exclude hospitalization and physical disease as complicating variables, but the possible effect of drug treatment was not explored.

The present study was designed to repeat the experiment on four controlled groups of patients covering all categories of schizophrenic states, and to determine whether ataractic medication influences their plasma fibrinogen concentration.

\section{METHODS}

SUBJECTS Patients were divided between the following four groups of 25 each on the basis of age and clinical history. All were free from known physical disease.

Group A (Chronic childhood psychosis) Subjects were diagnosed according to criteria proposed by a Working Party (1961) in this field. All presented with the picture of severe retardation and withdrawal, and their intellectual potential could not be determined. The majority also displayed hyperactivity with mannerisms and stereotyped movements. Their ages ranged from 6 to 16 years. All were residents of the Children's Cottages Training Centre, Kew, Victoria, Australia, and had been institutionalized for an average of six years, the range being one to 15 years. Drug treatment was suspended for one week before blood collection.

Group B (Acute schizophrenia) The patients, aged between 16 and 45 years, presented either at Melbourne University Department of Psychiatry or at the Royal Park Hospital. They included acute exacerbations of previously diagnosed schizophrenia. The criteria for diagnosis were similar to those described for Group C. Most had started phenothiazine treatment before admission to hospital. Blood samples were taken withing one week of presentation.

Group C (Chronic schizophrenia) Subjects were betwee 28 and 60 years old. The length of hospitalization wase between seven and 40 years, the first attack having occurred at least 10 years before admission. The criterio for selection was the establishment of passivity feeling or of a primary delusion; when neither of these symptoms was present a patient who showed at least four of the following five symptoms was diagnosed as schizophrenic: (1) the presence of delusions of elaboration; (2) the presence of schizophrenic thought disorder; (3) the presence of hallucinations; (4) flexibilitas cerea, catatonic episodes, or stereotypes; (5) ideas of reference.

Patients with known brain damage were excluded. They were housed in a ward of a mental hospital and treated uniformly in diet and as uniformly as possible in the regime adopted for their supervision.

Group D (Chronic geriatric schizophrenia) Patients were drawn from female wards of Kew Mental Hospital. Their age range was 51 to 80 years. They had a long history of paranoid and other delusions. The average period of hospitalization was 12 years. It was not possible to relinquish phenothiazine therapy at the time of blood collection.

Normal control groups consisted of mentally healthy individuals matched with patients for sex and as closely as possible for age. The children were outpatients of the Surgical Research Unit, Royal Children's Hospital, Melbourne. Controls for Group D were selected from inmates of Mount Royal Hospital, Parkville, and Greenvale Village for the Aged, Broadmeadows, Victoria. Hospital staff volunteers and blood donors made up the remainder. 
IURE Postprandial venous blood samples were dd and quickly transferred into glass bottles ing 200 i.u. heparin. Plasma fibrinogen conions were performed in duplicate using a ation (Brackenridge, 1960) of the heat suspension I of Stirland (1956).

\section{RESULTS}

; of the plasma fibrinogen concentrations in each of the psychotic and control groups nmarized in Table I. Before applying Student's to the differences between the means, use of riance ratio $F$ test showed that in each group ferences between sample variances were not ant. In Group D, and particularly in Group B, of $\boldsymbol{P}$ reached accepted levels of significance.

$\checkmark$ in Group $\mathrm{C}$ was it possible to examine the of drug treatment. Phenothiazines were awn from all 25 subjects for one month, hich blood samples were collected. Six months inalyses were again performed. Frequency utions of the plasma fibrinogen levels obtained tted in Histograms B and C (Fig. 1). Renewal lication led to an average increase of $39 \%$; red with the means of the control group and initial level, this result is highly significant 1.001). The final mean and S.D. of $613 \pm$ $\mathrm{ig} / 100 \mathrm{ml}$. represents an average rise of $108 \mathrm{mg} / 100 \mathrm{ml}$.

distribution in Histogram B is bimodal; the mode corresponds to that in Histogram $C$, e lower mode to that in Histogram A, which $s$ of the pooled normal groups. Histogram D displays the bimodality evident in $\mathbf{B}$. Thus le at the 300-399 class interval occurs in rams $A, B$, and $D$, while a mode at the 500-599 ll exists in Histograms B, C, and D

\section{DISCUSSION}

The significant elevation of fibrinogen content in acute (Group B) and geriatric chronic schizophrenia (Group D) supports the finding by Seal et al. (1967) of hyperfibrinogenaemia in both newly admitted and institutionalized schizophrenic subjects. It is pertinent to inquire into some possible reasons why significant increases were not reached in the remaining two groups of chronic patients. A few of the factors inadequately controlled by the normal groups include the effects of tranquillizing drugs, hospitalization, aspects of previous history such as stress, and genetic predispositions.

Hospitalization appears to be of little, if any, importance in view of the significant results obtained on the newly admitted patients of Seal et al. (1967), and those of Group B in the present series. It is therefore considered that diet, degree of exercise and activity, and other concomitants of institutional life play no major role in the causation of hyperfibrinogenaemia. No conclusions relating to the relevance of psychological and genetic factors can be drawn from the present study.

Stress has been linked with raised fibrinogen concentrations in two recent publications. Fessel (1965) found that the mean level of dextran-induced plasma turbidity, consisting mostly of precipitated fibrinogen, fell $66 \%$ in 18 prisoners when blood taken two weeks after a Parole Board hearing was compared with blood taken in the morning of the hearing. It was concluded that emotional stress, rather than any particular sort of mental disorder, was the prime contributor to the effect. Subsequently, Cameron and Dawson (1967) confirmed that levels of dextran-precipitable fibrinogen in newly admitted patients with depressive symptoms, anxiety states, schizophrenia, and hypomania varied

TABLE I

PLASMA FIBRINOGEN RESULTS IN FOUR GROUPS OF SCHIZOPHRENIC AND CONTROL SUBJECTS

\begin{abstract}
Males
Females
\end{abstract}

\begin{tabular}{l}
$\begin{array}{l}\text { Age } \\
\text { Mean }\end{array}$ \\
\hline$(y r)$ \\
\hline 12 \\
11 \\
27 \\
27 \\
44 \\
44 \\
69 \\
69
\end{tabular}

25

\begin{tabular}{lr}
\hline & 15 \\
controls & 15 \\
$\vdots$ & 15 \\
controls & 15 \\
$\vdots$ & 25 \\
controls & 25 \\
controls & 0
\end{tabular}

10
10
10
10
0
0
25
25

69

\begin{tabular}{r}
$S$. \\
\hline 3 \\
2 \\
8 \\
8 \\
10 \\
9 \\
7 \\
10
\end{tabular}

S.D.

$\frac{\begin{array}{l}\text { Fibrinogen level } \\ \text { Mean }\end{array}}{(m g / 100 m l .)}$

3505

2452

827

8397

$10 \quad 440$

9395

10
S.D.

$\begin{array}{ll}118 & 0.11 \\ 103 & \end{array}$

164

138

104

89

198

129
Significance of difference between means $(P)$

0.0045

0.12

0.027 

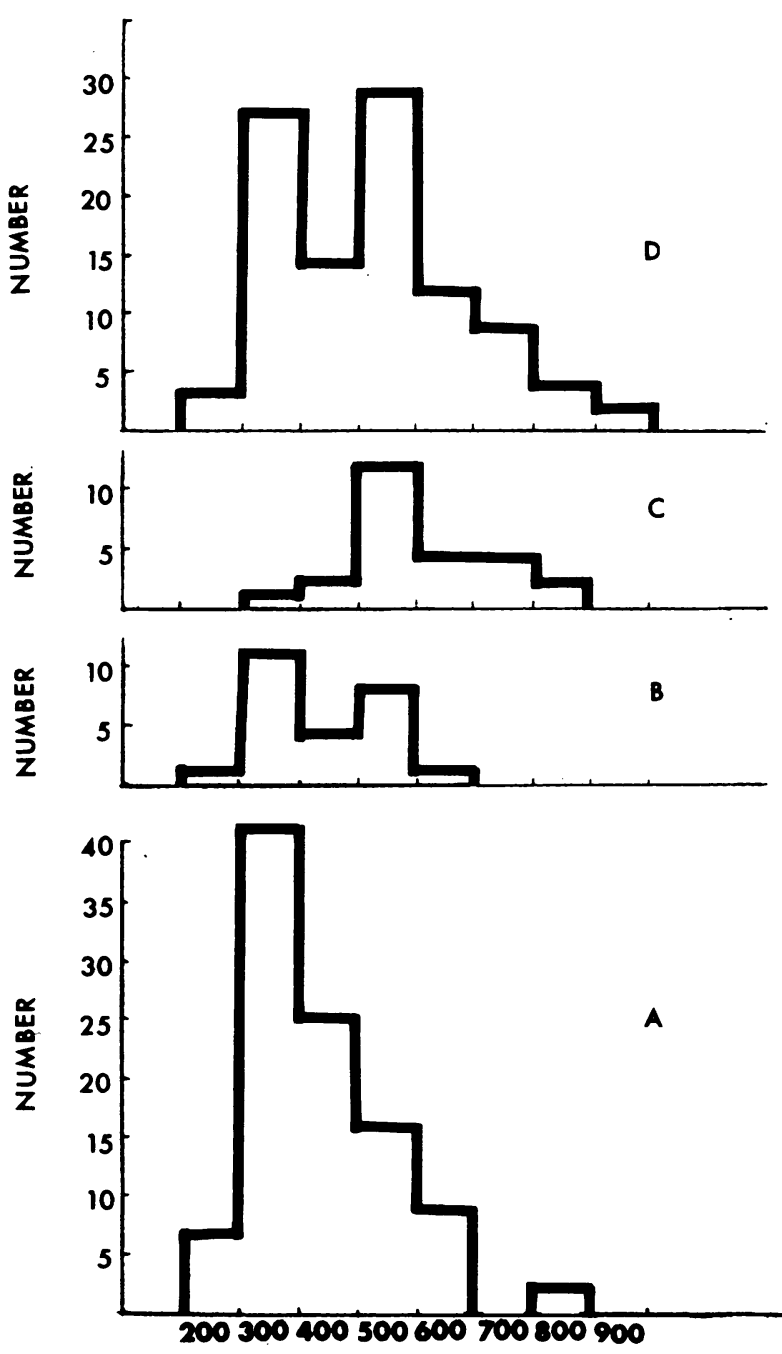

mg. FIBRINOGEN per $100 \mathrm{ml}$. plasma

FIG. 1. Frequency distributions of plasma fibrinogen concentrations in $(A) 100$ normal control subjects pooled from Groups $A, B, C$, and $D ;(B) 25$ Group $C$ schizophrenic patients, freed from drug treatment for one month; (C) the same 25 Group C patients six months after restoration of treatment; and (D) 100 schizophrenic patients pooled from Groups $A, B, C$, and $D$.

widely and bore no relation to diagnostic category. They supplied evidence that it provides a measure which responds to treatment, and advanced the hypothesis that it is a biochemical response to anxiety. The difficulty in ascribing the present hyperfibrinogenaemia to stress lies in establishing that
Groups B and D were under greater duress than Groups $\mathrm{A}$ and $\mathrm{C}$.

The observation that the increasing extent of medication among the groups is in the order of $\mathrm{C}$, A, B-D-which matches the order of significance C, A, D, and B found in Table I-immediately suggests a correlation between raised fibrinogen levels and the effects of phenothiazine therapy. The data of Fig. 1 confirm this impression. When the patients of Group B were again placed on tranquillizing drugs, the measure rose to a degree not attained by any of the groups. Reintroduction of treatment can be likened to medication of newly 등 admitted patients with acute symptoms, and the reported significance levels of $P<0.001$ and $0.0045 \vec{\Phi}$ for these groups is consistent with the hypothesis.

The bimodal frequency distributions observed in Fig. 1 can also be explained in this way. The mode $\overrightarrow{0}$ at the $300-399 \mathrm{mg} / 100 \mathrm{ml}$. interval represents the peak level in health (Histogram A) and after suspen- $\vec{\omega}$ sion of drug treatment (Fig. 1b). Its presence in Histogram D reflects the number of subjects, mainly in Groups $\mathrm{A}$ and $\mathrm{C}$, not receiving phenothiazines. $\omega$ On the other hand, the mode at the $500-599 \mathrm{mg} / \vec{A}$ $100 \mathrm{ml}$. interval represents the peak level in treated $\omega$ patients (Fig. 1c and d). Its occurrence in Histograr o $B$ may mean that withdrawal of medication for one month is insufficient time for the fibrinogen concentration to return to normal. It may tale ? several months to restore normal liver function subjects who have taken chlorpromazine fo prolonged periods (Yuwiler, Jenkins, and Du Kas. 1961).

Several reports have appeared describing changes in the levels of other plasma proteins synthesized by the liver following therapeutic doses of neuroleptic drugs (Trigos and McCullough, 1955; Carver, 1962). So far, however, their specific effect on $\frac{\square}{\varnothing}$ fibrinogen metabolism has apparently not been $\propto$ investigated. In the absence of evidence of physical $\overrightarrow{\vec{O}}$ disease and of widespread brain damage - which is 3 thought to be conducive to hyperfibrinogenaemia (Elliott and Buckell, 1961)-the pharmacological effect seems the most likely explanation of the results obtained in the four categories.

\section{SUMMARY}

Plasma fibrinogen concentrations have been $\delta$ measured in 100 schizophrenic patients allocated into four groups: (A) chronic, childhood, (B) acute, 윽 newly admitted, (C) chronic, middle aged, and $D$ (D) chronic, geriatric. In categories $B$ and $D$, the mean levels were significantly raised in relation to healthy control subjects matched for sex and age.

All Group $C$ patients had been deprived of tran- $N$ quillizing drugs for one month at the time of blood N 
collection. Six months after phenothiazine therapy was recommenced, the measure had risen by almost $40 \%$ to concentrations higher than those encountered in $B$ and $D$. The increase was significant at the level of $\boldsymbol{P}<0.001$. Frequency distributions of fibrinogen content were bimodal in $\mathrm{C}$ and when all schizophrenic groups were pooled. A single mode was present in $\mathrm{C}$ after treatment, and when all control groups were pooled.

These results have been interpreted as a biochemical response to pharmacotherapy. Alternative explanations, including the effects of hospitalization, stress, and cerebral tissue damage have also been considered.

We wish to thank Dr. Stoller, Chief Medical Officer, and the Mental Health Authority of Victoria for permission to examine patients under their care; Dr. T. Pierce and his staff, including Dr. J. Davies at Mont Park Hospital, for help in undertaking studies on their patients; Dr. D. Pitt and Mr. J. Lambley for providing blood samples from children in the Kew Children's Cottages Training Centre; Dr. C. McDonald for providing those from Kew Mental Hospital; and Dr. J. Cade and Dr. W. Walker for providing facilities and blood samples at Royal Park Hospital. Miss E. Hardley gave competent technical assistance. The support of the Mental Health Research Fund of the University of Melbourne is gratefully acknowledged.

\section{REFERENCES}

Bergen, J. R., Koella, W. P., Freeman, H., and Hoagland, H. (1962). A human plasma factor inducing behavioral and electro- physiological changes in animals. II. Changes induced in animals. Ann. N.Y. Acad. Sci., 96, 469-476.

Brackenridge, C. J. (1960). The interaction of plasma fibrinogen with anticoagulants in vitro. Clin. chim. Acta, 5, 552-558.

Cameron, I. A., and Dawson, J. (1967). The relationship between dextran precipitable fibrinogen and $170 \mathrm{H}$ corticosteroid levels in psychotic subjects. J. psychosom. Res., 11, 157-162.

Carver, M. J. (1962). Long-term study of chlorpromazine and meprobamate on serum protein profile. J. nerv. ment. Dis., 135, 126-130.

Elliott, F. A., and Buckell, M. (1961). Fibrinogen changes in relation to cerebrovascular accidents. Neurology (Minneap.), 11, 120-124.

Fessell, W. J. (1962a). Blood proteins in functional psychoses. Arch. gen. Psychiat., 6, 132-148.

- (1962b). Mental stress, blood proteins, and the hypothalamus. Arch. gen. Psychiat., 7, 427-435.

- (1965). Dextran turbidity: acute distress-phase reaction. Nature (Lond.), 205, 771-773.

Heath, R. G., and Krupp, I. M. (1967). Schizophrenia as an immunologic disorder. I. Demonstration of antibrain globulin by fluorescent antibody techniques. Arch. gen. Psychiat., 16, $1-9$.

- - - Byers, L. W., and Liljekvist, J. I. (1967a). Schizophrenia as an immunologic disorder. II. Effects of serum protein fractions on brain function. Arch. gen. Psychiat., 16, 10-23.

- - _ - _ - (1967b). Schizophrenia as an immunologic disorder. III. Effects of antimonkey and antihuman brain antibody on brain function. Arch. gen. Psychiat., 16, 24-33.

Seal, U. S., Swaim, W. R., and Eist, H. (1967). Hyperfibrinogenaemia in schizophrenia. Clin. Chem., 13, 160-162.

Stirland, R. M. (1956). A rapid method of estimating fibrinogen. Lancet, 1, 672.

Trigos, G., and McCullough, W. (1955). The protein profile in chlorpromazine therapy. Dis. nerv. Syst., 16, 309-311.

Working Party. (1961). Schizophrenic syndrome in childhood. Brit. med. J., 2, 889-890.

Yuwiler, A., Jenkins, I. M., and Du Kay, A. (1961). Serum oxidase tests and schizophrenia. Arch. gen. Psychiat., 4, 395-403. 